OPEN ACCESS

Edited by:

Cees Van Kooten,

Leiden University, Netherlands

Reviewed by:

Robert L. Fairchild,

Cleveland Clinic, United States

Josep M. Grinyó,

University of Barcelona, Spain

Maria-Luisa Alegre,

University of Chicago, United States

*Correspondence:

Gianluigi Zaza

gianluigi.zaza@univr.it

Specialty section:

This article was submitted to Alloimmunity and Transplantation,

a section of the journal

Frontiers in Immunology

Received: 29 September 2019 Accepted: 04 December 2019 Published: 19 December 2019

Citation: Zaza G, Leventhal J, Signorini L, Gambaro G and Cravedi P (2019) Effects of Antirejection Drugs on Innate Immune Cells After Kidney

Transplantation

Front. Immunol. 10:2978

doi: 10.3389/fimmu.2019.02978

\section{Effects of Antirejection Drugs on Innate Immune Cells After Kidney Transplantation}

\author{
Gianluigi Zaza ${ }^{1 *}$, Jeremy Leventhal ${ }^{2}$, Lorenzo Signorini ${ }^{1}$, Giovanni Gambaro ${ }^{1}$ and \\ Paolo Cravedi ${ }^{2}$
}

${ }^{1}$ Renal Unit, Department of Medicine, University-Hospital of Verona, Verona, Italy, ${ }^{2}$ Department of Medicine, Icahn School of Medicine at Mount Sinai, New York, NY, United States

Over the last decades, our understanding of adaptive immune responses to solid organ transplantation increased considerably and allowed development of immunosuppressive drugs targeting key alloreactive $T$ cells mechanism. As a result, rates of acute rejection dropped and short-term graft survival improved significantly. However, long-term outcomes are still disappointing. Recently, increasing evidence supports that innate immune responses plays roles in allograft rejection and represents a valuable target to further improve long-term allograft survival. Innate immune cells are activated by molecules with stereotypical motifs produced during injury (i.e., damage-associated molecular patterns, DAMPS) or infection (i.e., pathogen-associated molecular patterns, PAMPs). Activated innate immune cells can exert direct pro- and anti-inflammatory effects, while also priming adaptive immune responses. These cells are activated after transplantation by multiple stimuli, including ischemia-reperfusion injury, rejection, and infections. Data from animal models of graft rejection, show that inhibition of innate immunity promotes development of tolerance. Therefore, understanding mechanisms of innate immunity is important to improve graft outcomes. This review discusses effects of currently used immunosuppressive agents on innate immune responses in kidney transplantation.

\footnotetext{
Keywords: innate immunity, kidney transplantation, calcineurin inhibitors, mTOR-inhibitors, mycophenolate mofetil, glucocorticoids
}

\section{INTRODUCTION}

For many years, strategies to prevent allograft rejection have focused purely on preventing adaptive immunity. Recent evidence has increasingly indicated that pure focus on $\mathrm{T}$ and $\mathrm{B}$ cells is not sufficient to improve long-term renal transplant outcomes (1-3). Innate immune cells (e.g., dendritic cells, monocytes, macrophages, neutrophils, NK cells), via numerous mechanisms, play an important role in all major immunological events following kidney transplantation (4). During the peri-transplant period, innate immunity is activated by donor brain death, ischemiareperfusion injury, immunosuppression non-adherence, and infections-all of which increase risk for acute rejection (4-6). Late post-transplant innate immune cells produce an inflammatory microenvironment either in response to ongoing adaptive immune responses (e.g., chronic antibody mediated rejection) or independently, that enhances chronic allograft damage (7).

Innate immune cells are activated by common mechanisms. Molecules with stereotypical motifs produced during injury (i.e., damage-associated molecular patterns, DAMPS) or infection 
(i.e., pathogen-associated molecular patterns, PAMPs) initiate a variety of inflammatory events, including diapedesis, inflammatory cytokine production, and cell death (8). These pattern recognition receptor (PRR)-mediated inflammatory responses are necessary for microbial clearance. However, occurring post-transplant and resulting from release of endogenous PRR ligands, so-called "sterile inflammation," they can lead to severe and often irreversible graft tissue damage and fibrosis $(8,9)$. Importantly, these phenomena provide a link to adaptive immune responses through induced costimulatory molecule expression and cytokine-mediated "help."

Herein, we will review relevant literature regarding the impact of the main immunosuppressive agents employed in the maintenance phase of kidney transplantation (calcineurin inhibitors, mycophenolate mofetil/mycophenolic acid, corticosteroids, and mTOR inhibitors) on innate immune responses.

\section{CALCINEURIN INHIBITORS}

Calcineurin inhibitors (CNI), such as tacrolimus (TAC, FK506) and cyclosporine A (CsA), still represent the mainstay of immunosuppression in kidney transplantation. Their dominant mechanism of action is the inhibition of Nuclear Factor of Activated T-cells (NFAT) phosphorylation, with consequent reduction of IL-2-mediated $\mathrm{T}$ lymphocyte activation and proliferation $(10,11)$. CNI may also inhibit cytokines secretion and effective antigen presentation in innate immune cells, reducing their $\mathrm{T}$ cell priming capacity $(12,13)$. All these activities are primarily involved in the pathogenesis of acute rejection and other transplant-associated comorbidities.

Evidence shows that CsA blocks NFAT binding to the inducible NO synthase (iNOS) promoter, causing a reduction of iNOS expression and nitrite production in macrophages (14, 15). CsA can also down-regulate the enzyme cyclooxygenase2 (COX-2) in the kidney, which converts arachidonic acid into prostaglandin E2 (PGE2), an inflammatory mediator that modulates vascular permeability to expedite immune cell recruitment $(16,17)$.

CsA reduces the secretion of pro-inflammatory cytokines tumor necrosis factor (TNF)- $\alpha$ and IL-12 induced by LPS in human DCs $(12,18-20)$ and murine Langerhans cells $(21,22)$. On the other hand, CsA is able to increase the production of anti-inflammatory IL-10 in bone marrow derived DCs (BMDCs) and human blood-derived DCs induced by LPS $(12,18,21)$. The inhibition of IL-12 and the induction of IL-10 mediate the ability of CsA to promote an anti-inflammatory phenotype on these DCs with consequent differential regulation of effector $\mathrm{T}$ cell subsets.

This effect could be enhanced in patients treated with antithymocyte globulins. As reported by Naujokat et al. (23), DCs are potential targets of anti-thymocyte globulins (ATGs). These agents can bind cell surface receptors on DCs and regulate some of their major immunological functions.

CNI have also an inhibitory effect on Toll-like receptors (TLRs) dependent activation of monocytes/macrophages. In monocytes/macrophages from liver transplant recipients, therapeutic concentrations of CsA impaired IL-6 production in response to TLR2 and TLR7/8 activation, and TNF- $\alpha$ synthesis due to TLR7/8 stimulation, more than TAC (24). In renal transplant recipients, a switch from CsA to TAC caused a large monocytes/macrophages response, measured as TNF- $\alpha$, IL-1 $\beta$, IL-6, and IL-10 production, further supporting the higher inhibitory effects of CsA on monocytes compared to TAC (25). The impairment of TLR function affects the risk of graft rejection, infection, and disease recurrence after transplantation, and the difference impact of CsA and TAC on monocytes should be considered in the choice of immunosuppressant therapy in order to improve the outcomes (24).

Moreover, although there are not conclusive findings regarding the effects of maintenance immunosuppressive drugs on innate immunity and their impact on ischemia reperfusion, the study of Yang et al. (26) suggested that CsA was ineffective to control innate immunity following ischemia reperfusion injury (IRI). In fact, this medication increased the infiltration of Endothelin-1 (ED-1+) (a specific rat monocyte/macrophage marker) cells in tubulointerstitium and periglomerular areas in rat kidneys undergoing IRI. Centrally, TAC had an opposite effect. A similar trend was seen for several inflammation cytokines (26).

CNI may also influence immune cells by affecting their mitochondrial function (27). In macrophages, mitochondrial cardiolipin, ROS, and DNA trigger IL- $1 \beta$ secretion by activating the NLRP3 inflammasome (28) and mitochondrial antiviral signaling protein (MAVS) oligomerization, inducing type I IFN production (29) and NFKB activation (30). CsA inhibits inflammasome activation preventing mitochondrial membrane permeability transition (MPT), thereby reducing inflammatory cytokine secretion (28).

In neutrophils CNI are able to inhibit ROS generation and the formation of Neutrophil Extracellular Traps (NET) (31), causing important functional or pathological effects. In Rag2 ${ }^{-/-}$mice, lacking $\mathrm{B}$ and $\mathrm{T}$ cells, CNI treatment induced a rapid development of Candida albicans infections, indicating that CsA impairs specific anti-fungal functions in innate immune cells (32). More specifically, mice lacking calcineurin activity in neutrophils were defective in the ability to kill Candida albicans indicating that CsA may directly influence neutrophil killing processes (32).

Currently, overall mortality due to fungal infections in transplant patients varies between 25 and $80 \%$, with Candida and Cryptococcus species being the most commonly identified yeasts (33).

The higher doses of immunosuppressive medications in the first 6 months after transplantation are major causes of fungal infections. Ex vivo studies revealed that CsA damages human neutrophil clearance of Aspergillus fumigatus (another important cause of post-transplant opportunistic infections) (34), and that this effect is more evident in patients reaching high CNI trough levels. Inhibition of neutrophils activity by CNI may be, at least in part, responsible for increased risk of post-transplant fungal infections.

CNI do also affect NK cells in kidney transplant recipients (35). Zhang et al. have demonstrated that the expression levels 
of TNF-related apoptosis-inducing ligand (TRAIL) and FasL, potent apoptosis inducers, increase in NK cells at day 5 after transplantation, while their levels return to baseline on day 13 post-kidney transplantation (36). The authors also demonstrated that in supernatants generated from mixed lymphocytes culture (MLC) and on the surface of activated lymphocytes (particularly on NK cells) there was a significant increment of the expression of TRAIL and FasL. This condition was considerably reduced by adding CsA (500 ng/mL) at the beginning of MLC, an effect that could, at least in part, be implicated in the antirejection properties of CsA (36).

CsA inhibits the NK cells proliferation in a dose-dependent manner (37). Morteau et al. showed that ex vivo treatment of NK cells from healthy controls with CNI inhibits their degranulation and IFN- $\gamma$ production. Similar functional impairment was observed in NK cells from CNI-treated patients. This could have dramatic effects on the NK cells capacity of killing transformed or virus-infected cells and producing pro-inflammatory cytokines and could, at least in part, explain the increased risk of opportunistic infections and tumors of CNI-treated patients (38).

\section{MYCOPHENOLATE MOFETIL/MYCOPHENOLIC ACID}

Currently, mycophenolate mofetil (MMF) and its active metabolite mycophenolic acid (MPA), are the most widely used drugs in transplantation $(39,40)$. MMF/MPA are considered specific anti-lymphocytes agents, since they reduce the de novo guanosine nucleotide synthesis by selectively inhibiting the inosine monophosphate dehydrogenase (IMPDH), mainly expressed by T- and B- cells $(41,42)$.

When exposed to MMF/MPA, monocytes show lower levels of pro-inflammatory cytokine IL- $1 \beta$ and altered polarization, with enhanced expression of surface markers (like CD163 and CD200R), generally associated with an anti-inflammatory function (M2 phenotype) (43). Additionally, MMF/MPAexposed monocytes down-regulate several adhesion molecules, like ICAM-1, and display a weaker binding to cultured human umbilical vein endothelial cells (HUVEC) (44). Treating HUVECs alone with MMF/MPA does not reduce the adhesion of activated monocytes, reinforcing the idea of a direct effect of these compounds on monocytes (45).

In a mouse model of renal IRI, MMF down-regulated TLR4 expression on monocytes surface, along with plasma level of several cytokines (IL-6, MCP-1, and TNF- $\alpha$ ). This resulted in milder kidney damage, as defined by creatinine levels and histological findings at $48 \mathrm{~h}$ after IRI (46).

MMF also reduces the LPS-induced expression of MHCII on monocyte surface, suggesting a reduced activity as antigen presenting cells (44). In the presence of increasing MMF concentrations, human monocyte-derived dendritic cells (hMDDC) showed progressively less reactive phenotype. MMF treatment lowers the expression of costimulatory molecules (CD40, CD80, CD86), adhesion proteins (ICAM-1) and maturation markers (CD83, CD206), and decreases the synthesis of proinflammatory cytokines (TNF- $\alpha$, IL-10, IL-12, IL-18) and alloreactive T-cells stimulation (47). When exposed to MMF, monocytes do also display higher rates of apoptosis (48).

MPA and MMF have similar effects on hMDDCs activation and maturation, but MMF reduces, instead of increasing, IL-10 synthesis. This may support the concept that MPA has stronger protolerogenic effects on monocytes compared to MMF (49). It is likely that these effects are independent of IMPDH inhibition.

MMF/MPA have also modulating effects on NK cell activity. Similarly to mTOR inhibitors, they significantly reduce the proliferation of these cells and inhibit the expression of CD56, associated with a highly reactive phenotype (50,51). Accordingly, NK cells treated with these agents lose their cytotoxicity against K562 bone marrow target cells and reduced IFN- $\gamma$ production upon target encounter $(50,51)$.

Taking together, these data suggest that MMF/MPA impair differentiation, maturation and function of various innate immunity cells, which may represent an additional mechanism of their immunosuppressive effects. Whether similar mechanisms are shared with azathioprine, an antiproliferative agents with similar antirejection effects (52), is unclear.

\section{GLUCOCORTICOIDS}

Glucocorticoids (GCs) are anti-inflammatory drugs employed in both induction and maintenance phase of immunosuppression after kidney transplantation. They inhibit the inflammatory response and leukocyte migration into inflamed tissues. They also accelerate resolution of inflammation by inhibiting vascular permeability and leukocyte distribution/trafficking, and by modulating death/survival and cellular differentiation programs $(53,54)$.

Until recently, it has been thought that the anti-inflammatory effects of GCs were linked to their ability to inhibit regulator of genes encoding pro-inflammatory cytokines (e.g., NFкB and AP-1) through a mechanism called "transrepression" (55). However, additional mechanisms include: (1) transcription of genes able to negatively interfere with the synthesis of inflammatory mediators; (2) repression of genes mediating immune cells activation; (3) synergism between glucocorticoid receptor and transcription factors leading to the induction of anti-inflammatory genes $(56,57)$.

Glucocorticoids may also have direct effects on innate immune cells. In vitro, methylprednisolone-treated monocytes show increased expression of anti-inflammatory cytokines, like IL-10, with concomitant down-regulation of TNF- $\alpha$, IL- $1 \beta$, and IL-12 (58-60). Furthermore, GC-treated monocytes show lower expression levels of CD80 in response to inflammatory stimuli, which impairs their antigen-presenting activity (61). In vivo, data from methylprednisolone-treated kidney transplant patients, show increased numbers of $\mathrm{CD} 14^{++} \mathrm{CD}^{-} 6^{-}$(classical) and $\mathrm{CD}_{14}{ }^{++} \mathrm{CD}_{16}{ }^{+}$(intermediate) monocytes, while the $\mathrm{CD}_{14}{ }^{+} \mathrm{CD}_{16}{ }^{++}$(non-classical) population is declined compared to patients receiving $\mathrm{CNI}, \mathrm{MMF} / \mathrm{MPA}$ or $\mathrm{mTOR}$ inhibitor (62). This is consistent with recent observations showing a downregulation of TLR4 level on the surface of GC-treated monocytes. TLR4 is a pivotal element of the monocyte activation 
during sepsis, as well as in the acquired immune response to transplanted organs (63). GCs reduce the in vitro expression of TLR4 and the response to endotoxin in monocytes through the mediation of micro-RNA (MiR) 511-5p, a keystone in the anti-inflammatory effect of GCs (64).

GC affects also DC differentiation and maturation. In fact DC differentiated from human monocytes in presence of dexamethasone expressed lower levels of CD83 and CD86, lower APC function and a lower capacity to secrete TNF- $\alpha$ and IL- $1 \beta$ induced by CD40L and LPS than untreated cells $(65,66)$.

It is well-known that the administration of GCs induces neutrophilic leukocytosis, in particular by promoting neutrophil maturation and mobilization (67), an effect that is blocked by simultaneous inhibition of the L-selectin adhesion protein $(68,69)$.

The entire neutrophil activation process is also inhibited by GCs that reduce the expression of enzymes related to respiratory burst, such as NADPH oxidase, iNOS and COX-2 (70-73), as well as processes of chemotaxis, phagocytosis, and cytokines secretion $(74,75)$. In neutrophils, GCs simultaneously inhibit transcription factors related to pro and anti-inflammatory genes. The net effect is an increase in the expression of some receptors for interleukins and pro-inflammatory leukotrienes, such as IL1R1 and BLT1, (76-78), as well as a reduced sensitivity to apoptosis which increases neutrophils average life span (79).

$\mathrm{NK}$ are also sensitive to the effects of endogenous glucocorticoids under stress conditions, when steroids reduce NK cytolytic activity (80-82). Recent evidence shows that GCs can also induce the synthesis of pro-inflammatory cytokines through an epigenetic mechanism in NK cells. In particular, the expression of IL- 6 and INF- $\gamma$ is increased, along with a greater histone acetylation in the enhancer regions of these genes, which are thus more easily accessible to activating transcription factors $(83,84)$.

\section{THE MAMMALIAN TARGET OF RAPAMYCIN INHIBITORS: SIROLIMUS AND EVEROLIMUS}

The mammalian target of rapamycin (mTOR) is part of 2 different complexes (mTORC1 and mTORC2) with diverse signaling networks. mTORC1 promotes anabolic cellular metabolism stimulating synthesis of proteins, lipids, and nucleotides and, at the same time, inhibits catabolic processes, such as lysosome biogenesis and autophagy. mTORC2 controls cell survival, cytoskeleton organization, lipogenesis, and gluconeogenesis (85). In organ transplantation mTOR inhibitors, Sirolimus, and Everolimus, exert their immunosuppressive functions by preferentially inhibiting mTORC1 (86) thereby ostensibly halting protein translation necessary for effector $\mathrm{T}$ cell proliferation. Additional experimental and clinical experience with mTOR inhibitors support that they exert effects on graft survival, both beneficial and detrimental, in part by acting on innate immune cells $(87,88)$. Via changes in antigen presentation and costimulatory molecules, cytokine production, and metabolic pathways, mTOR inhibitors produce extensive, and sometimes conflicting, effects on innate immune cells.

The mTOR network allows innate immune cell maturation and costimulatory molecule expression during inflammation (89). As might be predicted, treatment with mTOR inhibitor impairs DCs maturation after LPS stimulation by reducing translation, including that of $\mathrm{MCH}-\mathrm{II}$ and costimulatory molecules (90). Rapamycin hampers functional and phenotypic maturation of DCs prompted by IL-4, LPS, or CD40 ligation (91-93) and impairs their ability to stimulate effector $\mathrm{T}$ cell proliferation. Similarly, DC development induced by fms-like tyrosine 3 kinase ligand (Flt3L), a powerful DC growth factor, is inhibited by rapamycin $(93,94)$. Accordingly, the DCs antigens uptake activity is impaired which further contributes to damaged allogeneic T lymphocytes stimulation $(90,95)$.

Conversely, mTOR inhibitors indirectly inhibit regulation of autophagy and promote this degradation with immunoregulatory capabilities. Importantly autophagy is a well-known contributor to both MHCII presentation and MHCI cross-presentation of exogenous peptides (96, 97). Increased antigen presentation increases the risk of activating adaptive immune responses and is an unintended and unwanted consequence of mTOR inhibitor use. In a murine liver transplant model, use of autophagy inhibitors improved graft and animal survival, although whether this was mediated by $\mathrm{MHC}$ presentation effects is unknown. Regardless, induction of innate immune cell autophagy is potential counterproductive side effect of mTOR inhibitor (98).

In immature DCs, mTOR inhibitors induce apoptosis by blocking the granulocyte-macrophage colony-stimulating factor (GM-CSF) signaling. Disruption in GM-CSF/PI3K/mTOR pathway produces a pro-apoptotic state, unbalancing anti- and pro-apoptotic mediators by reduction of the mitochondrial membrane potential (99). In mature DCs, PI3K/mTOR inhibition with increasing drug concentrations downregulates progressively several pro-inflammatory cytokines of the monocytic/macrophagic repertoire, in parallel with the reduction of phosphorylated Akt and p706K levels (90, 100, 101). In addition, mTOR inhibitor causes apoptosis in both human monocyte-derived and CD34+-derived DCs, without any effect in macrophages or myeloid cell lines (102).

mTOR inhibitors inhibit NK cell inflammatory capabilities by inhibiting their cytokine expressing and cytotoxic function. In particular, rapamycin impaired growth of the $\mathrm{CD}_{56}{ }^{\text {bright }} \mathrm{CD} 16^{+/-} \mathrm{NK}$ cell subset (associated with enhanced cytokine production) without affecting the amount of $\mathrm{CD} 56^{\mathrm{dim}} \mathrm{CD} 16^{+}$cells subset (with more cytotoxic capacity). With regards to the cytotoxic subset, mTOR inhibitors prevented NK cell expression of NKG2A and NCR (51). Absence of receptor ligation (if present) by target cells induces NK cell cytotoxic activity against the target cell. Prevention of their expression by mTOR inhibitors, therefore, impairs NK cell cytotoxic functioning. Overall, these results demonstrate that, mTOR inhibitors have distinct deleterious effects in immune cells which may have important implications in transplantation (51). 
TABLE 1 | Main effects of the immunosuppressive drugs on innate cells.

\begin{tabular}{|c|c|c|c|}
\hline Drug & Dendritic cells & Phagocytes & Natural Killer (NK) \\
\hline \multirow[t]{2}{*}{ CNIs } & $\begin{array}{l}\text { Reduce LPS-induced secretion of } \\
\text { pro-inflammatory cytokines TNF- } \alpha, \text { IL-12 } \\
(12,18-20) \text {. }\end{array}$ & $\begin{array}{l}\text { Impair IL- } 6 \text { and TNF- } \alpha \text { production in response } \\
\text { to TLR } 2 \text { and TLR7/8 activation in } \\
\text { monocytes/macrophages (24). }\end{array}$ & $\begin{array}{l}\text { Reduce the expression levels of TNF-related } \\
\text { apoptosis-inducing ligand (TRAIL) and } \\
\text { FasL (36). }\end{array}$ \\
\hline & $\begin{array}{l}\text { Increase LPS-induced production of IL-10 in } \\
\text { bone marrow derived DCs (BMDCs) and } \\
\text { human blood-derived DCs }(12,18,21) \text {. }\end{array}$ & $\begin{array}{l}\text { Inhibit inflammasome activation preventing } \\
\text { membrane permeability transition (MPT) in } \\
\text { monocytes/macrophages (28). }\end{array}$ & $\begin{array}{l}\text { Inhibit proliferation of NK cells in a } \\
\text { dose-dependent manner (37). }\end{array}$ \\
\hline
\end{tabular}

These effects may promote an anti-inflammatory phenotype on DCs that may lead to differential regulation of effector T cells subsets.

MMF/MPA Lower the expression of costimulatory molecules (CD40, CD80, CD86), adhesion proteins (ICAM-1) and maturation markers (CD83, CD206) (47).

Decrease the synthesis of proinflammatory cytokines (TNF- $\alpha$, IL-10, IL-12, IL-18) (47).

MMF reduces IL-10 synthesis (49).

GCs Reduce the production of TNF- $\alpha, \mathrm{IL}-1 \beta$ induced by CD40L and LPS $(65,66)$.

Inhibit the LPS-induced up-regulation of costimulatory molecules (e.g., CD40, CD80, CD83, CD86, and MHC-II) $(65,66)$.

$\mathrm{DC}$ differentiated in the presence of $\mathrm{GC}$ are not able to induce the proliferation of allogeneic CD4 T cells $(65,66)$.

mTOR inhibitors
Impair DC maturation after LPS stimulation by reducing translation, including that of $\mathrm{MHC}-\|$ and costimulatory molecules (90).

Prevent phenotypic and functional maturation induced by IL-4, LPS, or CD40 ligation (91-93).
Inhibit neutrophil's reactive oxygen species generation and the formation of Neutrophil Extracellular Traps (NET) (31).

This effect on neutrophil activity may be responsible for increased risk of post-transplant fungal infections.

Inhibit IL-1 $\beta$ production and enhance the expression of surface markers of $\mathrm{M} 2$ phenotype (CD163 and CD200R) in monocytes (43).

Down-regulate adhesion molecules, like ICAM-1 in monocytes and inhibit their adhesion to endothelial cells (44).

Down-regulate TLR-4 expression on monocytes surface in a mouse model of Ischemia reperfusion injury resulting in milder kidney damage (46)

Reduce the LPS-induced expression of MHC-\| on monocyte surface (44).

Induce apoptosis in monocytes (48).

Increase expression of anti-inflammatory

cytokines (IL-10) with concomitant

down-regulation of TNF- $\alpha, \mathrm{IL}-1 \beta, \mathrm{IL}-12$ in

monocytes (58-60).

In monocytes GCs reduce the expression of CD80 in response to inflammatory stimuli which impairs their antigen-presenting activity (61).

In kidney transplant patients, increase the number of CD14++CD16- and

CD14++CD16+ monocytes while the CD14+CD16++ population is declined compared to patients receiving $\mathrm{CNI}$, MMF/MPA or mTOR inhibitor (62).

Down-regulate TLR4 expression on the surface of monocytes and their response to endotoxin (64).

Inhibit activation process of neutrophils by reducing the expression of NADPH oxidase, iNOS, COX-2 (70-73).

Reduce chemotaxis, phagocytosis and cytokines secretion in neutrophils $(74,75)$. Increase the expression of some receptors for interleukins and pro-inflammatory leukotrienes such as IL1R1 and BLT1 in neutrophils (76-78).

Reduce sensitivity to apoptosis which increases neutrophils average life span (79).

In LPS-stimulated human monocytes reduce chemokines synthesis such as MCP-1, RANTES, IL-8, and MIP-1 (103).
Inhibit degranulation and IFN- $\gamma$ production (38).

Reduce proliferation of NK cells and inhibit the expression of CD56 $(50,51)$.

Reduce cytotoxicity against K562 bone marrow target cells and IFN- $\gamma$ production upon target encounter $(50,51)$.

Reduce NK cytolytic activity (80-82).

Through an epigenetic mechanism GCs induce the synthesis of pro-inflammatory cytokines $(83,84)$.

Inhibit NK proliferation and cytotoxicity capacity (51). 
TABLE 1 | Continued

\begin{tabular}{|c|c|c|c|}
\hline Drug & Dendritic cells & Phagocytes & Natural Killer (NK) \\
\hline & \multicolumn{3}{|l|}{ Inhibit DC development induced by Flt3L (93). } \\
\hline & $\begin{array}{l}\text { Impair antigen uptake contributing to damage } \\
\text { allogeneic T Iymphocytes stimulation (95). }\end{array}$ & $\begin{array}{l}\text { Induce the up-regulation of pathways involved } \\
\text { in production of nitric oxide, reactive oxygen } \\
\text { species and IL-12 in macrophages (105). }\end{array}$ & $\begin{array}{l}\text { Inhibit the shift toward an overall } \\
\text { NKG2A+KIR-NCR+ phenotype and maintain } \\
\text { an overall NKG2A-KIR+NCR+/- (51). }\end{array}$ \\
\hline & \multicolumn{3}{|l|}{$\begin{array}{l}\text { Disinhibit autophagy that contributes to both } \\
\text { MHCll presentation and } \mathrm{MHCl} \\
\text { cross-presentation of exogenous peptides } \\
(96,97) \text {. }\end{array}$} \\
\hline & \multicolumn{3}{|l|}{$\begin{array}{l}\text { Induce apoptosis in immature DC by blocking } \\
\text { GM-CSF signaling (99). }\end{array}$} \\
\hline & $\begin{array}{l}\text { Increase surface expression of chemokine } \\
\text { receptor CCR7 promoting DC migration into } \\
\text { lymphoid tissue (108). }\end{array}$ & & \\
\hline
\end{tabular}

An essential innate immune cell role involves production of cytokines. The mTOR inhibitors have pleiotropic effects that depend on the cells and circumstances studied. In LPS-stimulated human monocytes, mTOR inhibitors reduce several pro-inflammatory chemokines synthesis such as MCP1, RANTES, IL-8, and MIP-1 (103). Fine-needle aspiration biopsy (FNAB) samples (containing mononuclear cells together with kidney parenchymal cells) obtained from kidney transplant recipients receiving sirolimus showed lower synthesis of many proinflammatory cytokines, including IL-6 and MCP-1, and higher production of TGF- $\beta$ than samples from patients whose regimen contained MMF (104). Conversely, switch from a CNI based to a mTOR inhibitor-based regimen may worsen posttransplant inflammation. Gene expression profile on kidney samples showed the upregulation of pathways involved in production of NO, ROS, and IL-12 in macrophages and the activation of the adaptive immune response. Histological analysis confirmed a higher macrophages infiltration (105). Similarly, after shift from CsA to Sirolimus, the transcriptomic analysis on peripheral blood leucocytes showed a significant enrichment in pro-inflammatory pathways related to $\mathrm{NF \kappa B}$ and specific transcripts for monocyte and NK cells (106). It is noteworthy that the concomitant administration of mTOR inhibitors and GCs seem to cause a state of innate immune cell hyper-responsiveness, as if GCs action is override by the inhibition of mTOR (107).

mTOR inhibitor modulation of innate immune cells may contribute to a pro-tolerogenic state in the early phases of transplantation. Sordi et al. (108) showed that sirolimus, at clinically relevant concentrations and in contrast to calcineurin inhibitors, enhances the expression of CCR7 on the surface of human and mouse derived DCs with consequent expedite migration of DCs into lymphoid tissue. This condition may promote the tolerogenic effect of mTOR inhibitors, because these immune cells may reach appropriate $\mathrm{T}$ cell areas in the lymphoid tissue (109). Recent evidence challenged long-held notions that immunological memory is a feature exclusively for adaptive immunity. Evidence in monocytes showed that beta-glucan (a fungal antigen) experienced monocytes developed epigenetic changes spurred by accumulation of a cholesterol intermediate, mevalonate (110). Epigenetic changes were dependent on activation of mTOR to induce necessary downstream metabolic and histone changes. Importantly, using a strategy that included innate immune targeting rapamycin loaded nanoparticles, Braza et al. prevented macrophage trained immunity and extended graft survival indefinitely. These findings lead to an intriguing possibility that short term myeloid-specific nanoimmunotherapy that targets mTOR inhibitor in posttransplant may extend graft survival by preventing trained immunity generation (111).

There are controversial data about the impact of the m-TOR inhibitors on the regulation of I/R injury-related innate immune system in kidney transplantation. Several authors have suggested that these drugs may impair recovery of kidney function (112114) because of an anti-proliferative effects on tubular cells and an hyper-expression of several pro-inflammatory cytokines (e.g., IL1- $\beta$, IL-12, TNF- $\alpha$ ) and an inhibition of the production of antiinflammatory cytokines as IL-10. On the contrary, Macedo et al. have reported that $\mathrm{m}$-TOR inhibitors may protect from innate immunity activation (115). In particular the inhibition of mTOR may induce resistance to phenotypic maturation of DCs induced by inflammation and may facilitate the production of regulatory tolerogenic DCs.

\section{CONCLUSIONS}

In the past, great strides in allograft survival prolongation were attributed to successful suppression of adaptive immune responses (Table 1). A great body of literature, both clinical and basic science, attests to profound and diverse effects of modern immunosuppressive agents on innate immune cells. To make further progress improving transplant outcomes requires a more complete understanding of these effects and attempts to blunt current insufficiencies or vulnerabilities. As an example, clinical trials using monoclonal antibodies against innate immune receptors TLR2 (NCT01794663) and/or TLR4 (NCT01808469) to prevent delayed graft function and innate immune cell based therapies (including administration of regulatory macrophages and tolerogenic DCs) (116) may lead to new therapeutics that become standard of care to decrease the need for, or 
even completely replace, current immunosuppression regimens. These efforts to enlarge the post-transplant armamentarium by targeting innate immune cells will ideally lead to prolonged allograft function and minimized immunosuppression that extend allograft longevity without overly immunosuppressing and endangering the patient.

\section{REFERENCES}

1. Cucchiari D, Podestà MA, Ponticelli C. The critical role of innate immunity in kidney transplantation. Nephron. (2016) 132:227-37. doi: 10.1159/000444267

2. Janeway CA Jr. Approaching the asymptote? Evolution and revolution in immunology. Cold Spring Harb Symp Quant Biol. (1989) 54 (Pt 1):113. doi: 10.1101/SQB.1989.054.01.003

3. Hato $T$, Dagher PC. How the innate immune system senses trouble and causes trouble. Clin J Am Soc Nephrol. (2015) 10:1459-69. doi: 10.2215/CJN.04680514

4. Tecklenborg J, Clayton D, Siebert S, Coley SM. The role of the immune system in kidney disease. Clin Exp Immunol. (2018) 192:14250. doi: 10.1111/cei.13119

5. Brennan TV, Lunsford KE, Kuo PC. Innate pathways of immune activation in transplantation. J Transplant. (2010) 2010:826240. doi: 10.1155/2010/826240

6. Cainelli F, Vento S. Infections and solid organ transplant rejection: a cause-and-effect relationship? Lancet Infect Dis. (2002) 2:539-49. doi: 10.1016/S1473-3099(02)00370-5

7. Spahn JH, Li W, Kreisel D. Innate immune cells in transplantation. Curr Opin Organ Transplant. (2014) 19:149. doi: 10.1097/MOT.0000000000000041

8. Mogensen TH. Pathogen recognition and inflammatory signaling in innate immune defenses. Clin Microbiol Rev. (2009) 22:24073. doi: 10.1128/CMR.00046-08

9. Basset C, Holton J, O'Mahony R, Roitt I. Innate immunity and pathogen-host interaction. Vaccine. (2003) 21 (Suppl. 2):S12-23. doi: 10.1016/S0264-410X(03)00195-6

10. Fruman DA, Klee CB, Bierer BE, Burakoff SJ. Calcineurin phosphatase activity in T lymphocytes is inhibited by FK 506 and cyclosporin A. Proc Natl Acad Sci USA. (1992) 89:3686-90. doi: 10.1073/pnas.89.9.3686

11. Winslow MM, Gallo EM, Neilson JR, Crabtree GR. The calcineurin phosphatase complex modulates immunogenic B cell responses. Immunity. (2006) 24:141-52. doi: 10.1016/j.immuni.2005.12.013

12. Pino-Lagos K, Michea $\mathrm{P}$, Sauma D, Alba A, Morales J, Bono MR, et al. Cyclosporin A-treated dendritic cells may affect the outcome of organ transplantation by decreasing $\mathrm{CD} 4+\mathrm{CD} 25+$ regulatory $\mathrm{T}$ cell proliferation. Biol Res. (2010) 43:333-7. doi: 10.4067/S0716-976020100003 00010

13. Matsue H, Yang C, Matsue K, Edelbaum D, Mummert M, Takashima A. Contrasting impacts of immunosuppressive agents (rapamycin, FK506, cyclosporin A, and dexamethasone) on bidirectional dendritic cell-T cell interaction during antigen presentation. J Immunol. (2002) 169:355564. doi: 10.4049/jimmunol.169.7.3555

14. Fric J, Zelante $\mathrm{T}$, Wong AY, Mertes A, Yu HB, RicciardiCastagnoli P. NFAT control of innate immunity. Blood. (2012) 120:1380-9. doi: 10.1182/blood-2012-02-404475

15. Ranjan R, Deng J, Chung S, Lee YG, Park GY, Xiao L, et al. The transcription factor nuclear factor of activated $\mathrm{T}$ cells $\mathrm{c} 3$ modulates the function of macrophages in sepsis. J Innate Immun. (2014) 6:75464. doi: 10.1159/000362647

16. Höcherl K, Dreher F, Vitzthum H, Köhler J, Kurtz A. Cyclosporine A suppresses cyclooxygenase-2 expression in the rat kidney. J Am Soc Nephrol. (2002) 13:2427-36. doi: 10.1097/01.ASN.0000031702.86799.B9

17. Kirkby NS, Chan MV, Zaiss AK, Garcia-Vaz E, Jiao J, Berglund LM, et al. Systematic study of constitutive cyclooxygenase-2 expression: role of NF-кB and NFAT transcriptional pathways. Proc Natl Acad Sci USA. (2016) 113:434-9. doi: 10.1073/pnas.1517642113

\section{AUTHOR CONTRIBUTIONS}

GZ, JL, and PC searched the literature and wrote the manuscript. LS contributed to the literature search and literature analysis. GG and PC revised the manuscript. All authors read and approved the final manuscript.

18. Chen T, Guo J, Yang M, Han C, Zhang M, Chen W, et al. Cyclosporin A impairs dendritic cell migration by regulating chemokine receptor expression and inhibiting cyclooxygenase-2 expression. Blood. (2004) 103:413-21. doi: 10.1182/blood-2003-07-2412

19. Sauma D, Fierro A, Mora JR, Lennon-Duménil AM, Bono MR, Rosemblatt $\mathrm{M}$, et al. Cyclosporine preconditions dendritic cells during differentiation and reduces IL-2 and IL-12 production following activation: a potential tolerogenic effect. Transplant Proc. (2003) 35:2515-7. doi: 10.1016/j.transproceed.2003.09.020

20. Szabo G, Gavala C, Mandrekar P. Tacrolimus and cyclosporine A inhibit allostimulatory capacity and cytokine production of human myeloid dendritic cells. J Investig Med. (2001) 49:442-9. doi: 10.2310/6650.2001.33789

21. Tajima K, Amakawa R, Ito T, Miyaji M, Takebayashi M, Fukuhara S. Immunomodulatory effects of cyclosporin A on human peripheral blood dendritic cell subsets. Immunology. (2003) 108:321-8. doi: 10.1046/j.1365-2567.2003.01585.x

22. Campelo SR, da Silva MB, Vieira JL, da Silva JP, Salgado CG. Effects of immunomodulatory drugs on TNF- $\alpha$ and IL-12 production by purified epidermal langerhans cells and peritoneal macrophages. BMC Res Notes. (2011) 4:24. doi: 10.1186/1756-0500-4-24

23. Naujokat C, Berges C, Fuchs D, Sadeghi M, Opelz G, Daniel V. Antithymocyte globulins suppress dendritic cell function by multiple mechanisms. Transplantation. (2007) 83:48597. doi: 10.1097/01.tp.0000251975.81281.22

24. Howell J, Sawhney R, Testro A, Skinner N, Gow P, Angus P, et al. Cyclosporine and tacrolimus have inhibitory effects on toll-like receptor signaling after liver transplantation. Liver Transpl. (2013) 19:1099107. doi: $10.1002 /$ lt. 23712

25. Weimer R. Switch from cyclosporine A to tacrolimus in renal transplant recipients: impact on Th1, Th2, and monokine responses. Hum Immunol. (2000) 61:884-97. doi: 10.1016/S0198-8859(00)00152-X

26. Yang B, Jain S, Pawluczyk IZ, Imtiaz S, Bowley L, Ashra SY, et al. Inflammation and caspase activation in long-term renal ischemia/reperfusion injury and immunosuppression in rats. Kidney Int. (2005) 68:2050-67. doi: 10.1111/j.1523-1755.2005.00662.x

27. Halestrap AP, Connern CP, Griffiths EJ, Kerr PM. Cyclosporin A binding to mitochondrial cyclophilin inhibits the permeability transition pore and protects hearts from ischaemia/reperfusion injury. Mol Cell Biochem. (1997) 174:167-72. doi: 10.1023/A:1006879618176

28. Iyer SS, He Q, Janczy JR, Elliott EI, Zhong Z, Olivier AK, et al. Mitochondrial cardiolipin is required for Nlrp3 inflammasome activation. Immunity. (2013) 39:311-23. doi: 10.1016/j.immuni.2013.08.001

29. Agod Z, Fekete T, Budai MM, Varga A, Szabo A, Moon H, et al. Regulation of type I interferon responses by mitochondria-derived reactive oxygen species in plasmacytoid dendritic cells. Redox Biol. (2017) 13:63345. doi: 10.1016/j.redox.2017.07.016

30. Seth RB, Sun L, Ea CK, Chen ZJ. Identification and characterization of MAVS, a mitochondrial antiviral signaling protein that activates NF-kappaB and IRF 3. Cell. (2005) 122:669-82. doi: 10.1016/j.cell.2005.08.012

31. Gupta AK, Giaglis S, Hasler P, Hahn S. Efficient neutrophil extracellular trap induction requires mobilization of both intracellular and extracellular calcium pools and is modulated by cyclosporine A. PLoS ONE. (2014) 9:e97088. doi: 10.1371/journal.pone.0097088

32. Greenblatt MB, Aliprantis A, Hu B, Glimcher LH. Calcineurin regulates innate antifungal immunity in neutrophils. J Exp Med. (2010) 207:92331. doi: 10.1084/jem.20092531

33. Khan A, El-Charabaty E, El-Sayegh S. Fungal infections in renal transplant patients. J Clin Med Res. (2015) 7:371-8. doi: 10.14740/jocmr2104w 
34. Imbert S, Bresler P, Boissonnas A, Gauthier L, Souchet L, Uzunov M, et al. Calcineurin inhibitors impair neutrophil activity against Aspergillus fumigatus in allogeneic hematopoietic stem cell transplant recipients. $J$ Allergy Clin Immunol. (2016) 138:860-8. doi: 10.1016/j.jaci.2016.02.026

35. Shin BH, Ge S, Mirocha J, Karasyov A, Vo A, Jordan SC, et al. Regulation of anti-HLA antibody-dependent natural killer cell activation by immunosuppressive agents. Transplantation. (2014) 97:294-300. doi: 10.1097/01.TP.0000438636.52085.50

36. Zhang Y, Cheng G, Xu ZW, Li ZL, Song CJ, Li Q, Chen LH, et al. Down regulation of TRAIL and FasL on NK cells by Cyclosporin A in renal transplantation patients. Immunol Lett. (2013) 152:1-7. doi: 10.1016/j.imlet.2013.03.002

37. Si YQ, Bian XK, Lu N, Jia YF, Hou ZH, Zhang Y. Cyclosporine induces up-regulation of immunoglobulin-like transcripts 3 and 4 expression on and activity of NKL cells. Transplant Proc. (2012) 44:140711. doi: 10.1016/j.transproceed.2011.10.056

38. Morteau O, Blundell S, Chakera A, Bennett S, Christou CM, Mason $\mathrm{PD}$, Cornall RJ, et al. Renal transplant immunosuppression impairs natural killer cell function in vitro and in vivo. PLoS ONE. (2010) 5:e13294. doi: 10.1371/journal.pone.0013294

39. Kaltenborn A, Schrem H. Mycophenolate mofetil in liver transplantation: a review. Ann Transplant. (2013) 18:685-96. doi: 10.12659/AOT.889299

40. Mycophenolate Mofetil Acute Renal Rejection Study Group. Mycophenolate mofetil for the treatment of a first acute renal allograft rejection: three-year follow-up. The Mycophenolate Mofetil Acute Renal Rejection Study Group. Transplantation. (2001) 71:1091-7. doi: 10.1097/00007890-200104270-00014

41. Allison AC, Eugui EM. Mycophenolate mofetil and its mechanisms of action. Immunopharmacology. (2000) 47:85118. doi: 10.1016/S0162-3109(00)00188-0

42. Eickenberg S, Mickholz E, Jung E, Nofer JR, Pavenstadt HJ, Jacobi AM. Mycophenolic acid counteracts B cell proliferation and plasmablast formation in patients with systemic lupus erythematosus. Arthritis Res Ther. (2012) 14:R110. doi: 10.1186/ar3835

43. Kannegieter NM, Hesselink DA, Dieterich M, Kraaijeveld R, Rowshani AT, Leenen PJ, et al. The effect of tacrolimus and mycophenolic acid on CD14+ monocyte activation and function. PLoS ONE. (2017) 12:e0170806. doi: 10.1371/journal.pone.0170806

44. Glomsda BA, Blaheta RA, Hailer NP. Inhibition of monocyte/endothelial cell interactions and monocyte adhesion molecule expression by the immunosuppressant mycophenolate mofetil. Spinal Cord. (2003) 41:6109. doi: 10.1038/sj.sc.3101512

45. Laurent AF, Dumont S, Poindron P, Muller CD. Mycophenolic acid suppresses protein $\mathrm{N}$-linked glycosylation in human monocytes and their adhesion to endothelial cells and to some substrates. Exp Hematol. (1996) 24:59-67.

46. Zhang YX, Zhang JR, Wang ZG. Mycophenolate mofetil affects monocyte Toll-like receptor 4 signaling during mouse renal ischemia/reperfusion injury. Chin Med J. (2013) 126:1224-9. doi: 10.3760/cma.j.issn.0366-6999.20121542

47. Colic M, Stojic-Vukanic Z, Pavlovic B, Jandric D, Stefanoska I. Mycophenolate mofetil inhibits differentiation, maturation and allostimulatory function of human monocyte-derived dendritic cells. Clin Exp Immunol. (2003) 134:63-9. doi: 10.1046/j.1365-2249.2003. 02269.x

48. Nowak M, Tardivel S, Nguyen-Khoa T, Abreu S, Allaoui F, Fournier N, et al. Mycophenolate mofetil and rapamycin induce apoptosis in the human monocytic U937 cell line through two different pathways. J Cell Biochem. (2017) 118:3480-7. doi: 10.1002/jcb.26007

49. Lagaraine C, Hoarau C, Chabot V, Velge-Roussel F, Lebranchu Y. Mycophenolic acid treated human dendritic cells have mature migratory phenotype and inhibit allogeneic responses via direct and indirect pathways. Int Immunol. (2005) 17:351-63. doi: 10.1093/intimm/dxh215

50. Ohata K, Espinoza JL, Lu X, Kondo Y, Nakao S. Mycophenolic acid inhibits natural killer cell proliferation and cytotoxic function: a possible disadvantage of including mycophenolate mofetil in the graft-versus-host disease prophylaxis regimen. Biol Blood Marrow Transplant. (2011) 17:20513. doi: $10.1016 /$ j.bbmt.2010.08.014
51. Eissens DN, Van Der Meer A, Van Cranenbroek B, Preijers FW, Joosten I. Rapamycin and MPA, but not CsA, impair human NK cell cytotoxicity due to differential effects on NK cell phenotype. Am J Transplant. (2010) 10:1981-90. doi: 10.1111/j.1600-6143.2010.03242.x

52. Remuzzi G, Cravedi P, Costantini M, Lesti M, Ganeva M, Gherardi $\mathrm{G}$, et al. Mycophenolate mofetil versus azathioprine for prevention of chronic allograft dysfunction in renal transplantation: the MYSS follow-up randomized, controlled clinical trial. J Am Soc Nephrol. (2007) 18:197385. doi: 10.1681/ASN.2006101153

53. Steiner RW, Awdishu L. Steroids in kidney transplant patients. Semin Immunopathol. (2011) 33:157-67. doi: 10.1007/s00281-011-0259-7

54. Coutinho AE, Chapman KE. The anti-inflammatory and immunosuppressive effects of glucocorticoids, recent developments and mechanistic insights. Mol Cell Endocrinol. (2011) 335:213. doi: 10.1016/j.mce.2010.04.005

55. Adcock IM, Nasuhara Y, Stevens DA, Barnes PJ. Ligandinduced differentiation of glucocorticoid receptor (GR) transrepression and transactivation: preferential targetting of NF$\kappa \mathrm{B}$ and lack of I- $\mathrm{B}$ involvement. $\mathrm{Br} J$ Pharmacol. (1999) 127:1003-11. doi: 10.1038/sj.bjp.0702613

56. Xavier AM, Anunciato AK, Rosenstock TR, Glezer I. Gene expression control by glucocorticoid receptors during innate immune responses. Front Endocrinol. (2016) 7:31. doi: 10.3389/fendo.2016.00031

57. Escoter-Torres L, Caratti G, Mechtidou A, Tuckermann J, Uhlenhaut $\mathrm{NH}$, Vettorazzi S. Fighting the fire: mechanisms of inflammatory gene regulation by the glucocorticoid receptor. Front Immunol. (2019) 10:1859. doi: $10.3389 /$ fimmu.2019.01859

58. Visser J, van Boxel-Dezaire A, Methorst D, Brunt T, de Kloet ER, Nagelkerken L. Differential regulation of interleukin-10 (IL-10) and IL-12 by glucocorticoids in vitro. Blood. (1998) 91:4255-64. doi: 10.1182/blood.V91.11.4255

59. Lee SW, Tsou AP, Chan H, Thomas J, Petrie K, Eugui EM, et al. Glucocorticoids selectively inhibit the transcription of the interleukin 1 beta gene and decrease the stability of interleukin 1 beta mRNA. Proc Natl Acad Sci USA. (1988) 85:1204-8. doi: 10.1073/pnas.85.4.1204

60. Debets JM, Ruers TJ, van der Linden MP, van der Linden CJ, Buurman WA. Inhibitory effect of corticosteroids on the secretion of tumour necrosis factor (TNF) by monocytes is dependent on the stimulus inducing TNF synthesis. Clin Exp Immunol. (1989) 78:224-9.

61. Girndt M, Sester U, Kaul H, Hünger F, Köhler H. Glucocorticoids inhibit activation-dependent expression of costimulatory molecule B7-1 in human monocytes. Transplantation. (1998) 66:370-5. doi: 10.1097/00007890-199808150-00015

62. Rogacev KS, Zawada AM, Hundsdorfer J, Achenbach M, Held G, Fliser D, et al. Immunosuppression and monocyte subsets. Nephrol Dial Transplant. (2015) 30:143-53. doi: 10.1093/ndt/gfu315

63. Kaczorowski DJ, Nakao A, Mollen KP, Vallabhaneni R, Sugimoto R, Kohmoto J, et al. Toll-like receptor 4 mediates the early inflammatory response after cold ischemia/reperfusion. Transplantation. (2007) 84:127987. doi: 10.1097/01.tp.0000287597.87571.17

64. Curtale G, Renzi TA, Drufuca L, Rubino M, Locati M. Glucocorticoids downregulate TLR4 signaling activity via its direct targeting by miR-511-5p. Eur J Immunol. (2017) 47:2080-89. doi: 10.1002/eji.201747044

65. Rozkova D, Horvath R, Bartunkova J, Spisek R. Glucocorticoids severely impair differentiation and antigen presenting function of dendritic cells despite upregulation of Toll-like receptors. Clin Immunol. (2006) 120:26071. doi: 10.1016/j.clim.2006.04.567

66. Piemonti L, Monti P, Allavena P, Sironi M, Soldini L, Leone BE, et al. Glucocorticoids affect human dendritic cell differentiation and maturation. $J$ Immunol. (1999) 162:6473-81.

67. Cavalcanti DM, Lotufo CM, Borelli P, Ferreira ZS, Markus RP, Farsky SH. Endogenous glucocorticoids control neutrophil mobilization from bone marrow to blood and tissues in non-inflammatory conditions. Br J Pharmacol. (2007) 152:1291-300. doi: 10.1038/sj.bjp.07 07512

68. Lee D, Schultz JB, Knauf PA, King MR. Mechanical shedding of L-selectin from the neutrophil surface during rolling on sialyl Lewis $\mathrm{x}$ under flow. J Biol Chem. (2007) 282:4812-20. doi: 10.1074/jbc.M609994200 
69. Ricci E, Ronchetti S, Pericolini E, Gabrielli E, Cari L, Gentili M, et al. Role of the glucocorticoid-induced leucine zipper gene in dexamethasoneinduced inhibition of mouse neutrophil migration via control of annexin A1 expression. FASEB J. (2017) 31:3054-65. doi: 10.1096/fj.201601315R

70. Ignacchiti MD, Sesti-Costa R, Marchi LF, Chedraoui-Silva S, Mantovani B. Effect of academic psychological stress in post-graduate students: the modulatory role of cortisol on superoxide release by neutrophils. Stress. (2011) 14:290-300. doi: 10.3109/10253890.2010.545459

71. Dandona P, Aljada A, Ghanim H, Mohanty P, Hamouda W, Al-Haddad W. Acute suppressive effect of hydrocortisone on $\mathrm{p} 47$ subunit of nicotinamide adenine dinucleotide phosphate oxidase. Metabolism. (2001) 50:54852. doi: 10.1053/meta.2001.22511

72. Dandona P, Mohanty P, Hamouda W, Aljada A, Kumbkarni Y, Garg R. Effect of dexamethasone on reactive oxygen species generation by leukocytes and plasma interleukin-10 concentrations: a pharmacodynamic study. Clin Pharmacol Ther. (1999) 66:58-65. doi: 10.1016/S0009-9236(99)70054-8

73. Satoh S, Oishi K, Iwagaki A, Senba M, Akaike T, Akiyama $\mathrm{M}$, et al. Dexamethasone impairs pulmonary defence against Pseudomonas aeruginosa through suppressing iNOS gene expression and peroxynitrite production in mice. Clin Exp Immunol. (2001) 126:266-73. doi: 10.1046/j.1365-2249.2001.01656.x

74. Llewellyn-Jones CG, Hill SL, Stockley RA. Effect of fluticasone propionate on neutrophil chemotaxis, superoxide generation, and extracellular proteolytic activity in vitro. Thorax. (1994) 49:207-12. doi: 10.1136/thx.49.3.207

75. Hirsch G, Lavoie-Lamoureux A, Beauchamp G, Lavoie JP. Neutrophils are not less sensitive than other blood leukocytes to the genomic effects of glucocorticoids. PLoS ONE. (2012) 7:e44606. doi: 10.1371/journal.pone.0044606

76. Shieh JH, Peterson RH, Moore MA. Cytokines and dexamethasone modulation of IL-1 receptors on human neutrophils in vitro. J. Immunol. (1993) 150:3515-24.

77. Obinata H, Yokomizo T, Shimizu T, Izumi T. Glucocorticoids upregulate leukotriene $\mathrm{B} 4$ receptor-1 expression during neutrophilic differentiation of HL-60 cells. Biochem Biophys Res Commun. (2003) 309:114-9. doi: 10.1016/S0006-291X(03)01554-7

78. Langereis JD, Oudijk EJ, Schweizer RC, Lammers JW, Koenderman L, Ulfman LH. Steroids induce a disequilibrium of secreted interleukin-1 receptor antagonist and interleukin-1beta synthesis by human neutrophils. Eur Respir J. (2011) 37:406-15. doi: 10.1183/09031936.00170409

79. Liles WC, Dale DC, Klebanoff SJ. Glucocorticoids inhibit apoptosis of human neutrophils. Blood. (1995) 86:3181-8. doi: 10.1182/blood.V86.8.3181.3181

80. Bosch JA, Berntson GG, Cacioppo JT, Marucha PT. Differential mobilization of functionally distinct natural killer subsets during acute psychologic stress. Psychosom Med. (2005) 67:366-75. doi: 10.1097/01.psy.0000160469.00312.8e

81. Witek-Janusek L, Albuquerque K, Chroniak KR, Chroniak C, DurazoArvizu R, Mathews HL. Effect of mindfulness based stress reduction on immune function, quality of life and coping in women newly diagnosed with early stage breast cancer. Brain Behav Immun. (2008) 22:96981. doi: 10.1016/j.bbi.2008.01.012

82. Witek-Janusek L, Gabram S, Mathews HL. Psychologic stress, reduced NK cell activity, and cytokine dysregulation in women experiencing diagnostic breast biopsy. Psychoneuroendocrinology. (2007) 32:22-35. doi: 10.1016/j.psyneuen.2006.09.011

83. Krukowski K, Eddy J, Kosik KL, Konley T, Janusek LW, Mathews HL. Glucocorticoid dysregulation of natural killer cell function through epigenetic modification. Brain Behav Immun. (2011) 25:239-49. doi: 10.1016/j.bbi.2010.07.244

84. Eddy JL, Krukowski K, Janusek L, Mathews HL. Glucocorticoids regulate natural killer cell function epigenetically. Cell Immunol. (2014) 290:12030. doi: 10.1016/j.cellimm.2014.05.013

85. Zaza G, Granata S, Caletti C, Signorini L, Stallone G, Lupo A. mTOR inhibition role in cellular mechanisms. Transplantation. (2018) 102(2S Suppl. 1):S3-16. doi: 10.1097/TP.0000000000001806

86. Wullschleger S, Loewith $\mathrm{R}$, Hall MN. TOR signaling in growth and metabolism. Cell. (2006) 124:471-84. doi: 10.1016/j.cell.2006.01.016

87. Zaza G, Granata S, Tomei P, Masola V, Gambaro G, Lupo A. mTOR inhibitors and renal allograft: Yin and Yang. J Nephrol. (2014) 27:495506. doi: 10.1007/s40620-014-0103-y
88. Zaza G, Tomei P, Ria P, Granata S, Boschiero L, Lupo A. Systemic and nonrenal adverse effects occurring in renal transplant patients treated with mTOR inhibitors. Clin Dev Immunol. (2013) 2013:403280. doi: 10.1155/2013/403280

89. Weichhart $T$, Hengstschläger $M$, Linke $M$. Regulation of innate immune cell function by mTOR. Nat Rev Immunol. (2015) 15:599-614. doi: 10.1038/nri3901

90. Wang GY, Chen GH, Li H, Huang Y, Wang GS, Jiang N, et al. Rapamycin-treated mature dendritic cells have a unique cytokine secretion profile and impaired allostimulatory capacity. Transpl Int. (2009) 22:100516. doi: 10.1111/j.1432-2277.2009.00901.x

91. Taner T, Hackstein H, Wang Z, Morelli AE, Thomson AW. Rapamycintreated, alloantigen pulsed host dendritic cells induce ag-specific $\mathrm{T}$ cell regulation and prolong graft survival. Am J Transplant. (2005) 5:22836. doi: 10.1046/j.1600-6143.2004.00673.x

92. Turnquist HR, Raimondi G, Zahorchak AF, Fischer RT, Wang Z, Thomson AW. Rapamycin-conditioned dendritic cells are poor stimulators of allogeneic CD4+ T cells, but enrich for antigen-specific Foxp3 + T regulatory cells and promote organ transplant tolerance. J Immunol. (2007) 178:701831. doi: 10.4049/jimmunol.178.11.7018

93. Hackstein H, Taner T, Zahorchak AF, Morelli AE, Logar AJ, Gessner A, et al. Rapamycin inhibits IL-4 induced dendritic cell maturation in vitro and dendritic cell mobilization and function in vivo. Blood. (2003) 101:445763. doi: 10.1182/blood-2002-11-3370

94. Waskow C, Liu K, Darrasse-Jèze G, Guermonprez P, Ginhoux F, Merad $\mathrm{M}$, et al. The receptor tyrosine kinase Flt3 is required for dendritic cell development in peripheral lymphoid tissues. Nat Immunol. (2008) 9:67683. doi: 10.1038/ni.1615

95. Monti P, Mercalli A, Leone BE, Valerio DC, Allavena P, Piemonti L. Rapamycin impairs antigen uptake of human dendritic cells. Transplantation. (2003) 75:13745. doi: 10.1097/00007890-200301150-00025

96. Lee HK, Mattei LM, Steinberg BE, Alberts P, Lee YH, Chervonsky A, et al. In vivo requirement for Atg5 in antigen presentation by dendritic cells. Immunity. (2010) 32:227-39. doi: 10.1016/j.immuni.2009.12.006

97. Mintern JD, Macri C, Chin WJ, Panozza SE, Segura E, Patterson NL, et al. Differential use of autophagy by primary dendritic cells specialized in cross-presentation. Autophagy. (2015) 11:906-17. doi: 10.1080/15548627.2015.1045178

98. Gotoh K, Lu Z, Morita M, Shibata M, Koike M, Waguri S, et al Participation of autophagy in the initiation of graft dysfunction after rat liver transplantation. Autophagy. (2009) 5:351-60. doi: 10.4161/auto.5. 3.7650

99. Woltman AM, van der Kooij SW, Coffer PJ, Offringa R, Daha MR, van Kooten C. Rapamycin specifically interferes with GM-CSF signalling in human dendritic cells, leading to apoptosis via increased p27KIP1 expression. Blood. (2003) 101:1439-45. doi: 10.1182/blood-200206-1688

100. Xie S, Chen M, Yan B, He X, Chen X, Li D. Identification of a role for the $\mathrm{PI} 3 \mathrm{~K} / \mathrm{AKT} / \mathrm{mTOR}$ signaling pathway in innate immune cells. PLoS ONE. (2014) 9:e94496. doi: 10.1371/journal.pone.0094496

101. Ohtani M, Nagai S, Kondo S, Mizuno S, Nakamura K, Tanabe M, et al. Mammalian target of rapamycin and glycogen synthase kinase 3 differentially regulate lipopolysaccharide-induced interleukin-12 production in dendritic cells. Blood. (2008) 112:635-43. doi: 10.1182/blood-2008-02137430

102. Woltman AM, de Fijter JW, Kamerling SW, van Der Kooij SW, Paul LC, Daha MR, et al. Rapamycin induces apoptosis in monocyte and CD34derived dendritic cells but not in monocytes and macrophages. Blood. (2001) 98:174-80. doi: 10.1182/blood.V98.1.174

103. Lin HY, Chang KT, Hung CC, Kuo CH, Hwang SJ, Chen HC, et al. Effects of the mTOR inhibitor rapamycin on monocyte-secreted chemokines. BMC Immunol. (2014) 15:37. doi: 10.1186/s12865-014-0037-0

104. Oliveira JG, Xavier P, Sampaio SM, Henriques C, Tavares I, Mendes $\mathrm{AA}$, et al. Compared to mycophenolate mofetil, rapamycin induces significant changes on growth factors and growth factor receptors in the early days post-kidney transplantation. Transplantation. (2002) 73:91520. doi: 10.1097/00007890-200203270-00015 
105. Gallon L, Traitanon O, Sustento-Reodica N, Leventhal J, Ansari MJ, Gehrau $\mathrm{RC}$, et al. Cellular and molecular immune profiles in renal transplant recipients after conversion from tacrolimus to sirolimus. Kidney Int. (2015) 87:828-38. doi: 10.1038/ki.2014.350

106. Brouard S, Puig-Pey I, Lozano JJ, Pallier A, Braud C, Giral M, et al. Comparative transcriptional and phenotypic peripheral blood analysis of kidney recipients under cyclosporin A or sirolimus monotherapy. Am J Transplant. (2010) 10:2604-14. doi: 10.1111/j.1600-6143.2010. 03302.x

107. Weichhart T, Haidinger M, Katholnig K, Kopecky C, Poglitsch M, Lassnig C, et al. Inhibition of mTOR blocks the anti-inflammatory effects of glucocorticoids in myeloid immune cells. Blood. (2011) 117:427383. doi: 10.1182/blood-2010-09-310888

108. Sordi V, Bianchi G, Buracchi C, Mercalli A, Marchesi F, D’Amico $G$, et al. Differential effects of immunosuppressive drugs on chemokine receptor CCR7 in human monocyte derived dendritic cells: Selective up-regulation by rapamycin. Transplantation. (2006) 82:826-34. doi: 10.1097/01.tp.0000235433.03554.4f

109. Thomson AW, Turnquist HR, Raimondi G. Immunoregulatory functions of mTOR inhibition. Nat Rev Immunol. (2009) 9:324-37. doi: 10.1038/ nri2546

110. Bekkering S, Arts RJW, Novakovic B, Kourtzelis I, van der Heijden CDCC, Li Y, et al. Metabolic induction of trained immunity through the mevalonate pathway. Cell. (2018) 172:135-46.e9. doi: 10.1016/j.cell.2017.11.025

111. Braza MS, van Leent MMT, Lameijer M, Sanchez-Gaytan BL, Arts RJW, Pérez-Medina C, et al. Inhibiting inflammation with myeloid cell-specific nanobiologics promotes organ transplant acceptance. Immunity. (2018) 49:819-28.e6. doi: 10.1016/j.immuni.2018.09.008

112. Gonçalves GM, Cenedeze MA, Feitoza CQ, de Paula CB, Marques GD, Pinheiro HS, et al. The role of immunosuppressive drugs in aggravating renal ischemia and reperfusion injury. Transplant Proc. (2007) 39:41720. doi: 10.1016/j.transproceed.2007.01.027

113. Lieberthal W, Fuhro R, Andry C, Patel V, Levine JS. Rapamycin delays but does not prevent recovery from acute renal failure: role of acquired tubular resistance. Transplantation. (2006) 82:17-22. doi: 10.1097/01.tp.0000225772.22757.5e

114. Lui SL, Chan KW, Tsang R, Yung S, Lai KN, Chan TM. Effect of rapamycin on renal ischemia-reperfusion injury in mice. Transpl Int. (2006) 19:8349. doi: 10.1111/j.1432-2277.2006.00361.x

115. Macedo C, Turnquist HR, Castillo-Rama M, Zahorchak AF, Shapiro R, Thomson AW, et al. Rapamycin augments human DC IL-12p70 and IL-27 secretion to promote allogeneic Type 1 polarization modulated by NK cells. Am J Transplant. (2013) 13:2322-33. doi: 10.1111/ajt.12351

116. Hutchinson JA, Riquelme P, Sawitzki B, Tomiuk S, Miqueu P, Zuhayra $\mathrm{M}$, et al. Cutting edge: immunological consequences and trafficking of human regulatory macrophages administered to renal transplant recipients. J Immunol. (2011) 187:2072-8. doi: 10.4049/jimmunol.11 00762

Conflict of Interest: The authors declare that the research was conducted in the absence of any commercial or financial relationships that could be construed as a potential conflict of interest.

Copyright (C) 2019 Zaza, Leventhal, Signorini, Gambaro and Cravedi. This is an open-access article distributed under the terms of the Creative Commons Attribution License (CC BY). The use, distribution or reproduction in other forums is permitted, provided the original author(s) and the copyright owner(s) are credited and that the original publication in this journal is cited, in accordance with accepted academic practice. No use, distribution or reproduction is permitted which does not comply with these terms. 